\title{
Development of a new connection for precast concrete walls subjected to cyclic loading
}

\begin{abstract}
The Industrialized Building System (IBS) was recently introduced to minimize the time and cost of project construction. Accordingly, ensuring the integration of the connection of precast components in IBS structures is an important factor that ensures stability of buildings subjected to dynamic loads from earthquakes, vehicles, and machineries. However, structural engineers still lack knowledge on the proper connection and detailed joints of IBS structure construction. Therefore, this study proposes a special precast concrete wall-to-wall connection system for dynamic loads that resists multidirectional imposed loads and reduces vibration effects (PI2014701723). This system is designed to connect two adjacent precast wall panels by using two steel U-shaped channels (i.e., male and female joints). During casting, each joint is adapted for incorporation into a respective wall panel after considering the following conditions: one side of the steel channel opens into the thickness face of the panel; a U-shaped rubber is implemented between the two channels to dissipate the vibration effect; and bolts and nuts are used to create an extension between the two U-shaped male and female steel channels. The developed finite element model of the precast wall is subjected to cyclic loads to evaluate the performance of the proposed connection during an imposed dynamic load. Connection performance is then compared with conventional connections based on the energy dissipation, stress, deformation, and concrete damage in the plastic range. The proposed precast connection is capable of exceeding the energy absorption of precast walls subjected to dynamic load, thereby improving its resistance behavior in all principal directions.
\end{abstract}

Keyword: Industrial building system; Precast concrete structure; Precast wall connection; Finite element method; Nonlinear analysis; Energy dissipation; Concrete damage plasticity 